Gut, 1979, 20, 743-749

\title{
Reintroduction of gluten in adults and children with treated coeliac disease
}

\author{
PARVEEN J. KUMAR, D. P. O'DONOGHUE, KATHY STENSON, AND \\ A. M. DAWSON
}

From the Department of Gastroenterology, St. Bartholomew's Hospital, London

SUMmARY Twenty-eight patients, thought to have coeliac disease and on gluten free diets, were put on a normal diet to confirm their diagnoses. Nineteen had been diagnosed in adult life (ACD) and nine in childhood (CCD). Patients were assessed on jejunal, morphological, and symptomatic parameters. Eighteen patients with ACD relapsed within seven weeks. Nine patients with CCD relapsed at variable times but five took longer than seven weeks, the longest period being 10 months. Seven patients had no symptoms despite morphological deterioration during challenge and one patient, with ACD, did not relapse and was HLA B8 negative. This patient with ACD had subtotal villous atrophy on two jejunal biopsies and later showed morphological improvement on a gluten free diet. There was no correlation between the relapse time and time spent on a gluten free diet.

Coeliac disease has been described as a condition in which there is an abnormal jejunal mucosa which improves morphologically when treated with a gluten free diet and which deteriorates again on the reintroduction of gluten (Visakorpi, 1970; Meeuwisse, 1970). While the need for the latter part of this statement is well accepted in children, where a flat jejunal mucosa may be seen in such diseases as milk and soya protein intolerance (Ament and Rubin, 1972; Walker-Smith et al., 1978a, the necessity of a 'gluten challenge' in adults has been much disputed. In adult life in temperate climates an abnormial jejunal mucosa is usually only seen in such conditions as dermatitis herpetiformis (Marks et al., 1966), tropical sprue, and giardiasis, although in the latter two diseases it is rarely as severely affected as in coeliac disease. Nevertheless, adult patients who definitely require a challenge for diagnostic purposes are those who have been on gluten free diets without previous jejunal biopsies. An additional group may be those adults with atypical presentations whose jejunal lesions may need confirmation.

Unfortunately, for clinical practice, there are no established guide lines for gluten reintroduction; the time course for relapse on gluten being based on direct instillation of very large doses of crude or highly purified gluten into the jejunum. For this reason we have undertaken to map out the time course of symptomatic and morphological relapse

Received for publication 11 April 1979. in adults and children with treated coeliac disease by returning them to a normal diet. Moreover, in view of the variable response of patients to reintroducing gluten, we have also tried to find pointers that might help us in selecting patients for the confirmation of the disease by gluten challenge. For this reason we have correlated the relapse time with HLA status, age at diagnosis, and time spent on a gluten free diet.

\section{Methods}

Twenty-eight patients with treated coeliac disease were investigated. Nine patients (six female, three male) had been diagnosed in childhood (childhood coeliac disease-CCD) at a mean age of 7.6 years (age 1-13 years). These patients were investigated at a mean age of $16 \cdot 1$ years (14-21 years) when they had been on a gluten free diet for an average of 6.4 years (1-14 years). Seven of these patients had had symptoms in the first year of life.

Nineteen ( 15 female) patients had been diagnosed in adult life (adult coeliac disease-ACD) aged 34.6 years (range 16-57 years) and were investigated when they had been on a gluten free diet for 2.8 years (range 0.75-7 years). On questioning, eight patients said they had symptoms in childhood.

Permission was obtained from all patients and parents (of the CCD group) to undergo the gluten reintroduction after the nature of the study had been explained. 
DESIGN OF STUDY

All patients were treated as outpatients and had a jejunal biopsy before the challenge. They were then told to eat a normal diet containing at least four slices of bread ( $10 \mathrm{~g}$ gluten) per day. Further jejunal biopsies were taken at the onset of symptoms or, at any event, in the first three weeks and then at intervals thereafter. Twelve patients had their first biopsies within the first week; the remaining patients, because of family, work, and school commitments, had their first biopsies within the next two weeks. A relapse was defined as gross morphological deterioration as seen under a dissecting microscope with or without the presence of symptoms.

\section{JEJUNAL BIOPSIES}

These were taken under fluoroscopic control at a point distal to the duodenojejunal flexure. Specimens were laid flat, mucosal surface upwards, on ground glass slides and fixed in $10 \%$ formalin for routine histological processing. Morphometric studies, measuring surface cell heights, villous heights, and intraepithelial lymphocyte counts were performed using an eyepiece micrometer (Stewart et al., 1967; Ferguson and Murray, 1971).
HISTOCOMPATIBILITY ANTIGENS

Twenty-five patients were HLA typed using the cytotoxicity method.

\section{STA TISTICS}

Statistical analysis was performed using Wilcoxon's sum of ranks for unmatched data.

\section{Results}

\section{INTESTINAL BIOPSIES}

An average of 3.75 biopsies per patient (range two to five biopsies) were performed, although half the patients required only two biopsies.

\section{Histology}

Table 1 shows the histological data of the pre- and post-challenge biopsies.

PRE-CHALLENGE BIOPSY

Surface cell heights (normal range $>29$ ). The average surface cell height in the ACD group was $31 \cdot 7 \mu$ (range 22.8 to $37 \cdot 2 \mu$ ) with four patients below the normal range. In the CCD group the average was $31.4 \mu$ (range 26.7 to $37 \cdot 8 \mu$ ) with two patients

Table 1 Clinical and histological data before and after gluten reintroduction in patients with coeliac disease

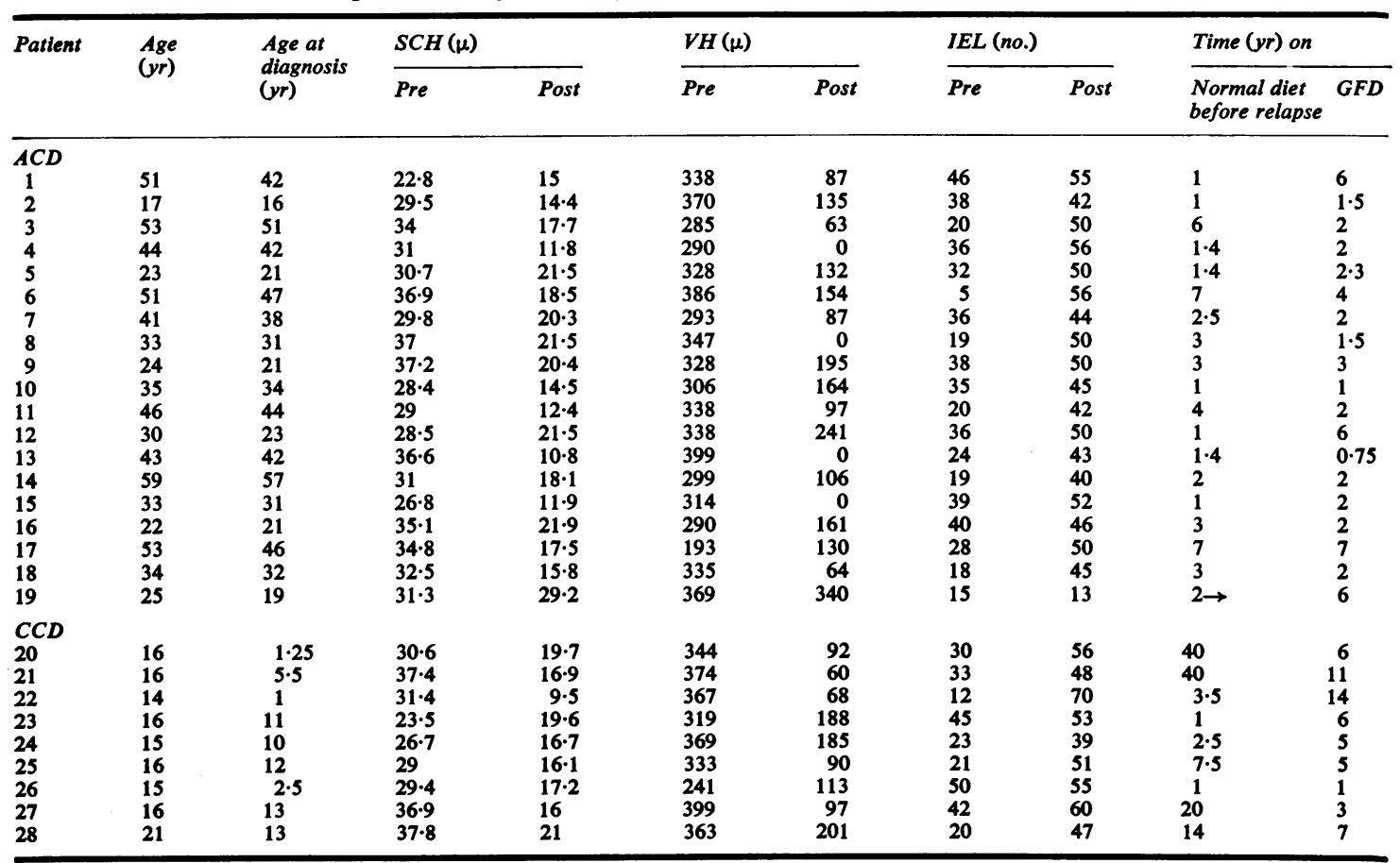

ACD: adult coeliac disease. CCD: childhood coeliac disease. SCH: surface cell height. VH: villous height. IEL: intraepithelial lymphocyte count. GFD: gluten free diet 
below the normal range. The mean villous height (normal range $>330 \mu$ ) in the ACD group was $324 \mu$ (range 285-399 $\mu$ ) with eight patients just below the normal range (Fig. 1). In the CCD group (Fig. 2) the mean VH was $345 \mu$ (range 319 to $399 \mu$ ) with two patients below the normal range. The mean intra- epithelial lymphocyte count (IEL normal range up to 40 lymphocytes/100 epithelial cell) was $29(5-46)$ in the ACD group and 31 (12-50 in the CCD group) with one ACD and three CCD patients above the normal range.

There were no significant differences between the

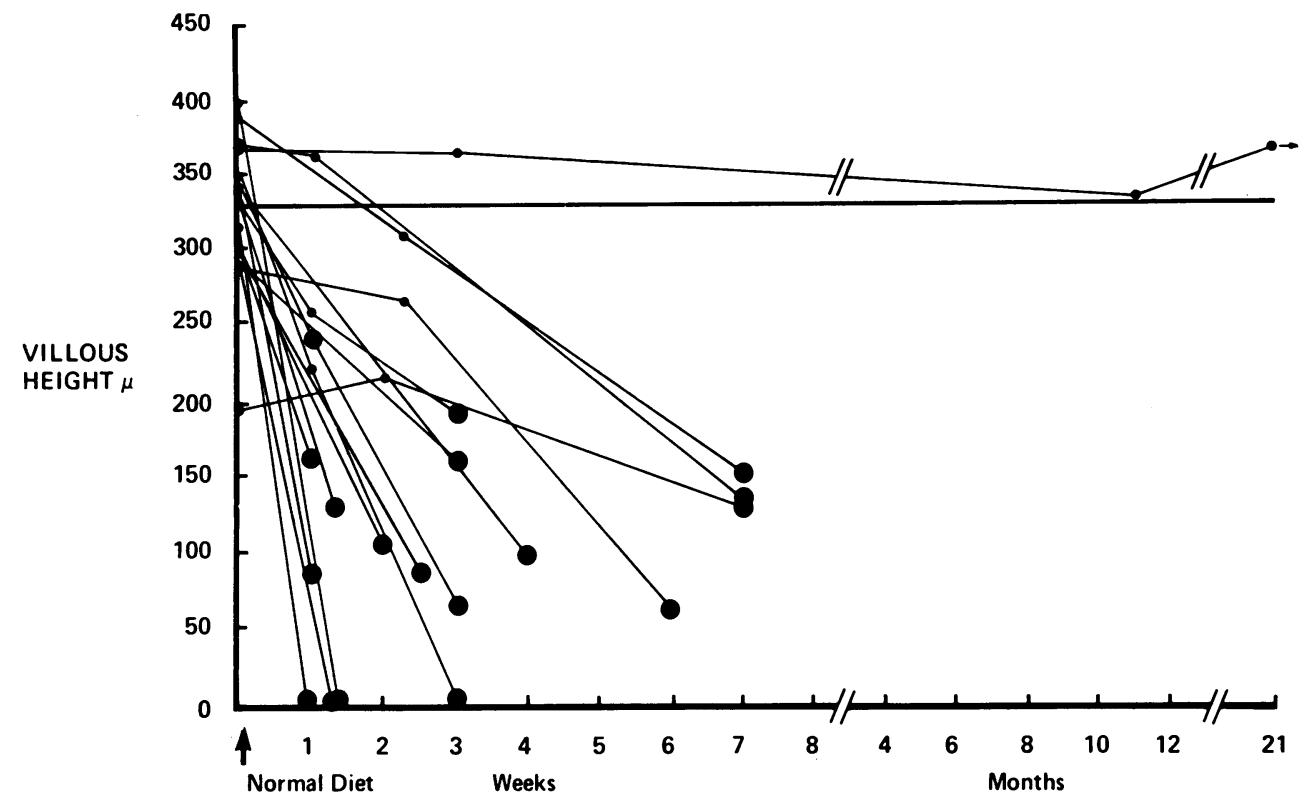

Fig. 1 Graph showing the villous heights in patients with adult coeliac disease during the reintroduction of gluten. Each small dot represents a jejunal biopsy and large dots represent a time when relapse had occurred.

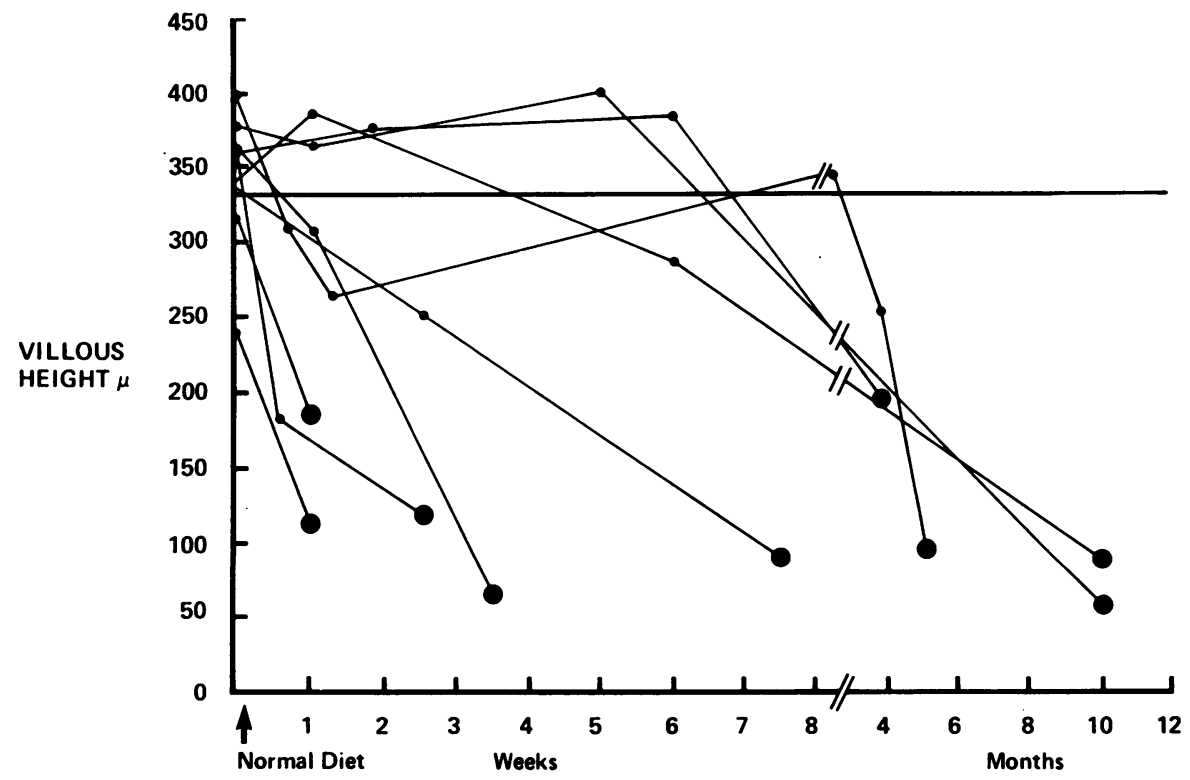

Fig. 2 As in Fig. 1 but showing patients with childhood coeliac disease. 
ACD and CCD groups in any of these measurements.

\section{Post-challenge biopsies}

Twenty-seven patients showed gross deterioration after gluten reintroduction. One patient with ACD had a normal biopsy at two years. There were no significant differences in surface cell height, villous height, or intraepithelial lymphocyte count between the CCD and ACD groups after challenge.

\section{TIMING OF MORPHOLOGICAL RELAPSE}

(Table 2, Figs 1 and 2)

The time of relapse on a normal diet was very variable. As a group, patients with $C C D$ took longer to relapse than patients with ACD but, despite this, two patients with CCD relapsed in the first week. All 18 ACD patients who relapsed had relapsed within seven weeks. Two patients with CCD took 10 months to relapse; these two had jejunal biopsies at one week and at five and six weeks, showing little change. They were subsequently followed up on blood samples and at 10 months one showed a low serum and red cell folate, and the other had mild symptoms. The 'late' adult relapses who had been on a normal diet for between three and seven weeks were biopsied because of symptoms and were shown to have relapsed.

TIMING OF SYMPTOMS (Tables 2 and 3)

Three patients with CCD and three with ACD had no symptoms at all despite a morphological relapse in five. Eight patients had symptoms, mainly of

Table 2 Time of histological relapse and time of onset of symptoms during gluten reintroduction

\begin{tabular}{|c|c|c|c|c|c|}
\hline & & \multicolumn{3}{|c|}{ Time of relapse } & \multirow[t]{2}{*}{ No relapse } \\
\hline & & $<2 / 12$ & & $<2 / 12$ & \\
\hline $\begin{array}{l}\text { Histological } \\
\text { relapse }\end{array}$ & $\begin{array}{l}\text { CCD } \\
\text { ACD }\end{array}$ & $\begin{array}{l}5 \\
18 \\
\text { Hours }\end{array}$ & Days & $\begin{array}{c}4 \\
0 \\
\text { Weeks }\end{array}$ & $\begin{array}{l}0 \\
1 \\
\text { Nil }\end{array}$ \\
\hline Symptoms & $\begin{array}{l}\text { CCD } \\
\text { ACD }\end{array}$ & $\begin{array}{l}1 \\
0\end{array}$ & $\begin{array}{l}3 \\
4\end{array}$ & $\begin{array}{r}2 \\
12\end{array}$ & $\begin{array}{l}3 \\
3\end{array}$ \\
\hline
\end{tabular}

Table 3 Symptoms at time of relapse in patients on gluten containing diet

\begin{tabular}{lccc}
\hline & \multicolumn{2}{l}{ Symptoms on relapse } \\
\cline { 2 - 4 } & Total no. & ACD & CCD \\
\hline Diarrhoea & 9 & 6 & 3 \\
Tiredness & 11 & 7 & 4 \\
Distension & 6 & 5 & 1 \\
Unwell & 7 & 5 & 2 \\
Pain & 4 & 4 & 0 \\
Mood changes & 3 & 0 & 3 \\
Mouth ulcers & 2 & 2 & 0 \\
No symptoms & 6 & 3 & 3 \\
\hline
\end{tabular}

tiredness in the first week. Symptoms of feeling unwell and tiredness appeared within a few hours in a patient with CCD; another patient with CCD complained of distension and vomiting in two days, and one with ACD complained of nausea and mouth ulcers in four days. Most patients who had symptoms had them after the first week.

The commonest sympton was tiredness followed closely by diarrhoea, distension, and feeling unwell. It was interesting that 19 patients did not have diarrhoea. Four patients complained of pain; in two this was sharp: one had odd niggles and the last had back pain similar to that she had had before the initial diagnosis of coeliac disease was made.

\section{HLA STATUS}

Twenty-five (six CCD, 19 ACD) patients had their HLA status determined and $80 \%$ of these were HLA B8 positive. Five patients with CCD and 10 with ACD were HLA A1, B8 positive, while four (one CCD and three ACD) were HLA A2 B8. The patient who did not relapse was HLA B8 negative.

\section{CORRELATION OF RELAPSE TIME}

WITH HLA STATUS

There was no correlation between the HLA status of the patients and the time taken for relapse, the presence or absence of symptoms, or a history of childhood symptoms in the ACD group.

\section{CORRELATION OF RELAPSE TIME WITH TIME}

\section{SPENT ON GLUTEN FREE DIET BEFORE}

CHALLENGE

There was no significant correlation in either the ACD or CCD group with time spent on a gluten free diet. Equally, there was no correlation with the time spent on a normal diet before diagnosis-that is, age at diagnosis-with relapse rate.

\section{Case history}

ADULT PATIENT WHO DID NOT RELAPSE

Patient no. 19, A.W. (a woman who was born on 28 March 1951), was asymptomatic in infancy and childhood. At the age of 18 years she developed pain and swelling of her knees (with normal radiographs) and later nausea and vomiting after meals. A year later she developed loose, slimy, offensive stools and lost $19 \cdot 1 \mathrm{~kg}$. (3 stones) in weight over nine months. She was admitted to another hospital where a flat jejunal biopsy was considered to be compatible with a diagnosis of coeliac disease. She was put on a gluten free diet and haematinics for her anaemia. She made little improvement and was readmitted three months later with another episode of painful bilateral swelling of the knees lasting 36 hours. 
Lactose and sucrose were removed from her diet but this made little difference. She continued to have severe fatty diarrhoea and weight loss and eventually developed marked carpopedal spasms and was transferred to our hospital. On investigation she looked ill and was grossly wasted. She had a serum total protein of $50 \mathrm{~g} / \mathrm{l}(5 \mathrm{~g})$, low serum albumin of $26 \mathrm{~g} / \mathrm{l}(2.6 \mathrm{mg} / \mathrm{dl})$, a serum calcium of $2 \cdot 12 \mathrm{mmol} / \mathrm{l}$
$(8.6 \mathrm{mg} / \mathrm{dl})$ and alkaline phosphatase of $9 \mathrm{KA}$ units. Gastrointestinal function tests showed an abnormal xylose tolerance test and a fat excretion of $12 \mathrm{~g} /$ day on a low fat diet $(\mathrm{n}=6 \mathrm{~g} /$ day $)$. Her Schilling test part II was $0.5 \%(n=10 \%)$ and part III (with pancreatic supplements) showed an absorption of $2 \cdot 7 \%$ (abnormal). There were no pancreatic enzymes in the duodenal juice after a Lundh meal. A further
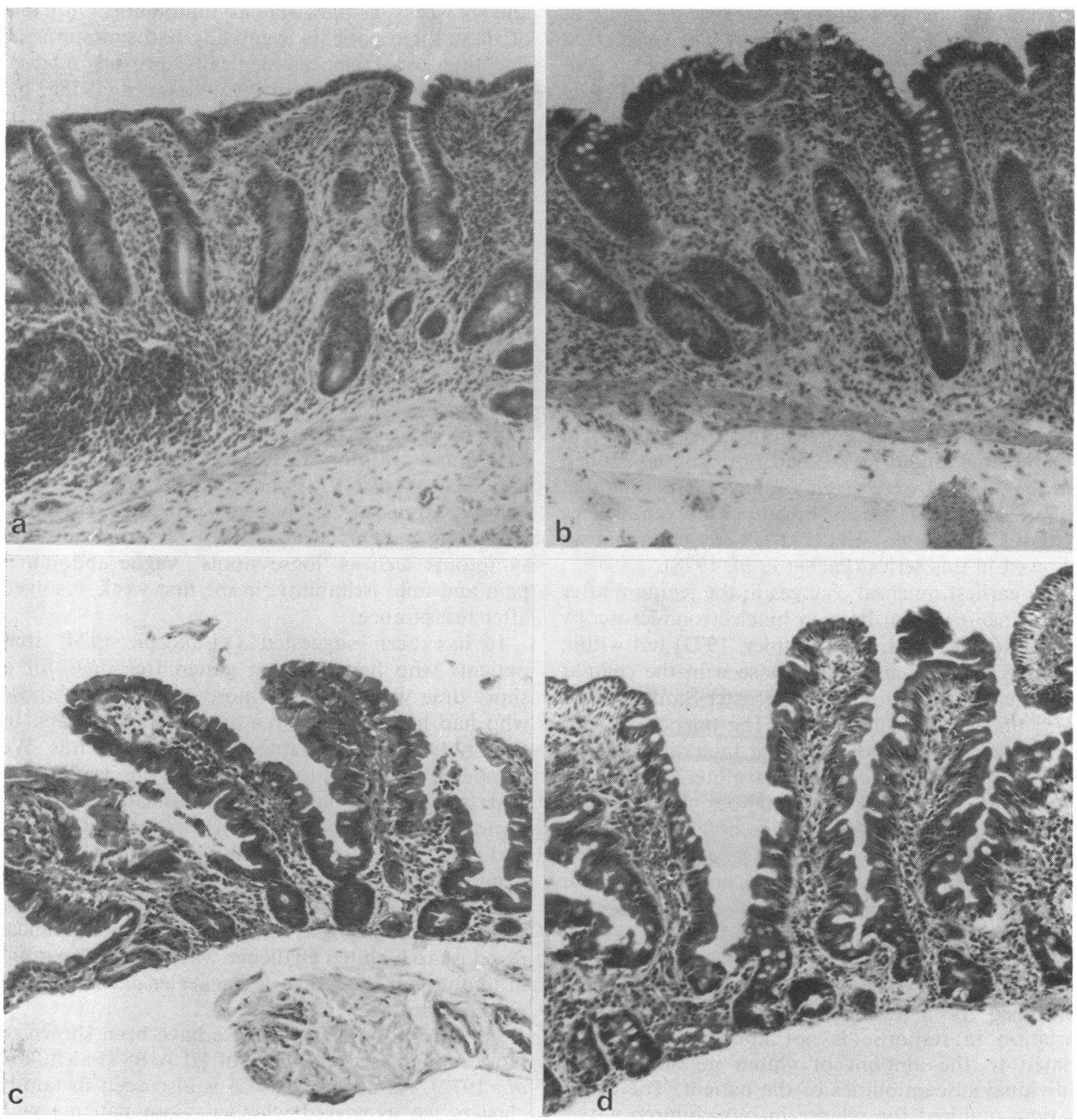

Fig. 3 Patient no. 19. Histological sections of jejunal biopsies. (a) Jejunal biopsy on diagnosis showing subtotal villous atrophy. (b) Jejunal biopsy a few months after starting a gluten free diet. (c) Biopsy taken after 18 months on a gluten free diet. (d) Biopsy taken after 24 months on a normal gluten containing diet. 
jejunal biopsy showed subtotal villous atrophy. The patient continued on her gluten free diet with the addition of pancreatic supplements but it was 18 months before she achieved clinical, morphological, and functional response. Three additional jejunal biopsies over the six years on a gluten free diet showed a gradual return towards a normal mucosa. It was felt this patient had severe coeliac disease with secondary pancreatic deficiency. She was HLA B8 negative. Her joints continued to cause intermittent problems and at the age of 25 years she was started on penicillamine. Six years after starting her gluten free diet the patient requested a gluten challenge. She has now been on a normal diet for over two years and remains extremely well with a normal jejunal mucosa (Fig. 3).

\section{Discussion}

There is, as yet, no established procedure for the reintroduction of gluten for diagnostic purposes in patients with treated coeliac disease. Rolles et al. (1975) gave $20 \mathrm{~g}$ per day of commercial gluten powder to their patients, whereas Hamilton and McNeil (1972) used one slice of bread per day (approximately $2.5 \mathrm{~g}$ gluten). In other studies, in children, the gluten intake had not been controlled and the patients were given a gluten containing diet with at least four slices of bread per day (equivalent to about $10 \mathrm{~g}$ gluten) and that is the system that we followed in this series (Packer et al, 1978).

The earliest mucosal changes in the jejunum after gluten ingestion can be seen by electronmicroscopy (Shiner and Ballard, 1972; Shiner, 1973) but within 24 to 48 hours changes can be seen in the cellular infiltrate of the jejunum (Lancaster-Smith et al., 1975) under light microscopy. The purpose of this paper was to establish the time interval required, after the reintroduction of dietary gluten, to produce gross jejunal mucosal abnormalities easily visible under dissecting and light microscopic examination, and to map out the time course of clinical and morphological relapse in children and adults. Our results indicate that the time required for relapse is very variable in both children and adult patients. However, all adult patients who relapsed had done so within seven weeks, whereas some of the children continued for a few months. The reason for this variation in response is not known but may be related to the amount of gluten ingested or the individual susceptibilities of the patient. The extent of time required for relapse in our children agrees with the work of Visakorpi (1974) who found that $90 \%$ of his children showed a deterioration of the mucosa during the first six months on challenge with a normal diet and the rest in less than 12 months. The work of Packer and her colleagues (1978) suggests that, in children, a normal biopsy during challenge at three to four months on a normal diet would exclude the diagnosis of coeliac disease, as none of these patients relapsed at a later date. We are unable to compare directly our studies with those of Packer and her colleagues as our patients with childhood coeliac disease who relapsed at five, 10 and 10 months had their penultimate biopsies at 18 , six, and six weeks, as they were asymptomatic. Only one of these three patients eventually had symptoms at the time of their histologically proven relapse. Walker-Smith (1972) and his colleagues (1978a, b), however, have shown normal intestinal mucosa in children back on a normal diet at six months and 14 months. There are no published data to compare directly our results in adult patients.

The development of symptoms during the challenge period was a very unreliable indication of gluten-induced mucosal abnormalities. Seven patients felt extremely well despite morphological relapse in five. However, all patients with symptoms eventually relapsed, although in a few cases the symptoms antedated morphological deterioration by several days. This unreliability of symptoms as a guide for relapse is in agreement with Visakorpi (1974) who found symptoms in only a third of his patients and Packer et al. (1978) who found definite symptoms in only four of 25 patients. In the remainder (including patients who did not relapse) equivocal symptoms such as 'loose stools', vague abdominal pain and mild irritability, in the first week, resolved after reassurance.

It has been suggested (Visakorpi, 1974) that patients who had been on gluten free diets for a short time would relapse more quickly than those who had had a gluten free diet for many years. In this study we were unable to demonstrate this. We wondered whether the corollary to this was truethat is, whether the patients who had been on a normal diet for longer periods, and therefore had had a prolonged sensitisation with antigenic gluten, would relapse more quickly. However, we found no correlation between the age, diagnosis and relapse time. Rolles et al., (1975) found that a clinical response to a gluten challenge was much more rapid in infants but the study of Packer et al., (1978) did not confirm this.

Patients with coeliac disease have been shown to have an increased incidence of HLA B8 (Falchuk et al., 1972). As coeliac disease is also seen in family clusters we wondered whether those patients who were B8 positive would be more sensitive to gluten and thus relapse earlier than B8 negative patients. This, however, was shown not to be true in this series. Similarly, there was no correlation between 
HLA status and patients who had symptoms during challenge.

However, the only patient who did not relapse was HLA B8 negative and her case was extremely surprising. She presented as an extremely ill patient with gross malabsorption and a flat jejunal biopsy, despite rather atypical clinical features. However, to subscribe to the strict definition of a non-coeliac subject at this stage (two years) she needs continued follow-up for at least another two years. If she is, indeed, not a coeliac, a case could be made for challenging all adult patients with coeliac disease who are not HLA B8 positive. In our series one of six B8 negative patients did not relapse as compared with none of 20 patients who were B8 positive, in a condition where approximately $80 \%$ of patients are B8 positive.

We would like to thank the National Fund for Research into Crippling Diseases and the Joint Research Board, St. Bartholomew's Hospital. We are grateful to Dr. D. R. K. Medley of Princess Alexandra Hospital, Harlow, Essex, for originally referring patient A. W. and to Dr. J. Harries of the Institute of Child Health and Dr. J. Walker-Smith for referring patients with coeliac disease who have outgrown their clinics.

\section{References}

Ament, M. E., and Rubin, C. E. (1972). Soy protein-another cause of the flat intestinal lesion. Gastroenterology, 62, 227-234.

Falchuk, Z. M., Rogentine, G. N., and Strober, W. (1972). Predominance of histocompatibility antigen HLA B8 in patients with gluten-sensitive enteropathy. Journal of Clinical Investigation, 51, 1602-1605.

Ferguson, A., and Murray, D. (1971). Quantitation of intra epithelial lymphocytes in human jejunum. Gut, 12, 988-994.
Hamilton, J. R., and McNeill, L. K. (1972). Childhood celiac disease: response of treated patients to a small uniform daily dose of wheat gluten. Journal of Pediatrics, 81, 885-893.

Lancaster-Smith, M., Kumar, P. J., and Dawson, A. M. (1975). The cellular infiltrate of the jejunum in adult coeliac disease and dermatitis herpetiformis following reintroduction of dietary gluten. Gut, 16, 683-688.

Marks, J., Shuster, S., and Watson, A. J. (1966). Small-bowel changes in dermatitis herpetiformis. Lancet, 2, 1280-1282.

Meeuwisse, G. (1970). Diagnostic criteria in coeliac disease. Acta Paediatrica Scandinavica, 59, 461-463.

Packer, S. M., Charlton, V., Keeling, J. W., Risdon, R. A., Ogilvie, D., Rowlatt, R. J., Larcher, V. F., and Harries, J. T. (1978). Gluten challenge in treated coeliac disease. Archives of Disease in Childhood, 53, 449-455.

Rolles, C. J., Anderson, C. M., and McNeish, A. S. (1975). Confirming persistence of gluten intolerance in children diagnosed as having coeliac disease in infancy. Archives of Disease in Childhood, 50, 259-263.

Shiner, M. (1973). Ultrastructural changes suggestive of immune reactions in the jejunal mucosa of coeliac children following gluten challenge. Gut, 14, 1-12.

Shiner, M., and Ballard, J. (1972). Antigen-antibody reactions in the jejunal mucosa in childhood coeliac disease after gluten challenge. Lancet, 1, 1202-1205.

Stewart, J. S., Pollock, D. J., Hoffbrand, A. V., Mollin, D. L., and Booth, C. C. (1967). A study of proximal and distal intestinal structure and absorptive function in idiopathic steatorrhoea. Quarterly Journal of Medicine, 36, 425-444.

Visakorpi, J. K. (1970). An international enquiry concerning the diagnostic criteria of coeliac disease. Acta Paediatrica Scandinavica, 59, 463-464.

Visakorpi, J. K. (1974). Definition of coeliac disease in childhood. In Coeliac Disease, pp. 10-16. Edited by W. T. J. M. Hekkens and A. S. Pena. Stenfert Kroese: Leyden.

Walker-Smith, J. A. (1972). Transient gluten intolerance (letter). Archives of Disease in Childhood, 47, 155.

Walker-Smith, J. A., Harrison, M., Kilby, A., Phillips, A., and France, N. (1978a). Cows' milk-sensitive enteropathy. Archives of Disease in Childhood, 53, 375-380.

Walker-Smith, J. A., Kilby, A., and France, N. E. (1978b). Reinvestigation of children previously diagnosed as coeliac disease. In Perspectives in Coeliac Disease, p. 267. Edited by B. McNicholl, C. F. McCarthy, and P. F. Fottrell. MTP Press: Lancaster. 